\title{
Editorial and preface to thematic issue on biohydrology
}

\author{
L’ubomír Lichner
}

Institute of Hydrology, Slovak Academy of Sciences, Račianska 75, 83102 Bratislava, Slovakia. E-mail: lichner@uh.savba.sk

\section{VILIAM NOVÁK IS SEVENTY}

It is unbelievable, but true: this young-looking man is really seventy. It is marvellous that he is still in high spirits, able to solve complicated problems in soil hydrology, lead the Department of Soil Hydrology at the Institute of Hydrology of the Slovak Academy of Sciences (IH SAS), helping Ph.D. students and postdocs, and even running marathons 8 times per year!

After obtaining his degree in civil engineering at the Slovak Technical University in Bratislava in 1964, he joined with the IH SAS, where he has worked continuously ever since. He has also held on to the topic of evaporation nearly all this time, which resulted in the nicest gift for his anniversary: a monograph entitled "Evapotranspiration in the Soil-PlantAtmosphere System", published by Springer (Novák, 2012). Among other responsibilities over the years, he has served as a member of the Scientific Council of the Slovak Technical University in Bratislava (1992-1995), and as member of the Presidium of the Slovak Academy of Sciences in Bratislava (1998-2005). He was also the Editor-in-Chief of the Journal of Hydrology and Hydromechanics (JHH) for 19 years (19942012), during which he managed to get the journal indexed in Scopus, Science Citation Index Expanded, and other abstracting and indexing databases.

Dear Viliam, I have great pleasure in conveying to you on behalf of JHH Editorial Board and in my own name, our warmest congratulations upon the occasion of the 70th anniversary of your birthday. Your life-long devotion to science and brilliant achievements over many years have set an example for the coming generations.

\section{CHANGES IN JOURNAL OF HYDROLOGY AND HYDROMECHANICS}

The current changing of the guard, at the helm of the journal, gives us an opportunity to implement a number of changes that have been discussed in the past and are becoming increasingly needed. The gradual decrease of the Impact Factor of the journal over the last few years $(2009 \mathrm{IF}=1.000,2010 \mathrm{IF}=0.570$, $2011 \mathrm{IF}=0.340$ ) forces us to make several changes in the $\mathrm{JHH}$, as recommended by Marzena Falkowska (Versita) and Enikő Tóth Szász (Thomson Reuters). From now on, English is the only language to be used in JHH. The hydrology themes will be limited to biohydrology, catchment hydrology and vadose zone hydrology, primarily of temperate zone. The amount of articles published per year will increase to 40 . The percentage of editorial board members coming from Western Europe and North America, will be increased to almost $50 \%$. We are also going to increase the percentage of authors, coming from Western Europe and North America, and ask outstanding scientists to submit their review and research papers for our journal. We hope that these changes will help us to increase and stabilize the JHH Impact Factor, and get this journal into Current Contents Connect database.

\section{PREFACE TO THEMATIC ISSUE ON BIOHYDROLOGY}

This Thematic Issue on Biohydrology is intended to serve as a greeting for the $3^{\text {rd }}$ Biohydrology conference to be held in Landau, Germany, from the 21 st to the 24th of May 2013. The papers presented in this Thematic issue provide a cross-section of topics covering the interactions between living organisms and hydrology.

The biological origin of soil water repellency (SWR) suggests that it will have a high spatial and temporal variability at a small scale because of the submillimeter spatial variability of organic matter, organisms and the microbial environment in soil. In this context, Bachmann et al. (2013) introduce a new and easy-to-apply operation for measuring the spatial distribution of SWR, using a modified sessile drop method for direct optical assessment of contact angle at a small scale. Knowledge about the spatial distribution of SWR at the small scale may help to improve the understanding of water and solute transport in water repellent soils.

Caballero et al. (2013) compare the biohydrology of a cloud forest with forests at lower elevations using a simple water balance model suitable for these environments. The cloud forest watershed has a distinctly smaller amount of plant-available water and greater groundwater storage, resulting in watershed discharges that were four times greater than those of the other watersheds, despite only relatively minor differences in annual rainfall amount. These differences are caused by both the geology (as it affected topography and stream network) and biological effect of the cloud forest on the water storage in the root zone.

Chanie et al. (2013) study the extent of harm of Eucalyptus on the ecosystem in the semi humid Ethiopian Highlands. Poor performances of adjacent plants, particularly maize and undergrowth plants, are due to light, water and nutrients (total nitrogen, available phosphorus and exchangeable calcium) competition and soil water repellency. Based on these results, the impacts of Eucalyptus on soil properties and moisture content are limited to a great extent to $20 \mathrm{~m}$ away from the tree.

Plant species with different root systems have dissimilar erosion-reducing effects. Himmelbauer et al. (2013) study the impact of NPK fertilization on shoot and root growth of Bromus innermis L. and Lotus corniculatus L. on gentle $\left(6^{\circ}\right)$ and steep $\left(12^{\circ}\right)$ slopes. These authors observe that the effect of fertilization is stronger on the gentle than on the steep slopes, and treatments with the highest root mass density on both slopes showed the greatest potential for reducing erosion.

Nikodem et al. (2013) assess the impact of different vegetation on the distribution of rainfall (due to throughfall and stemflow), water regime, and $\mathrm{Al}$ and $\mathrm{SO}_{4}{ }^{2-}$ leaching from forest soils at two elevation transects in Jizera Mountains. The effect of the precipitation redistribution on water regime is considerable in the beech forest, but it is almost negligible in the spruce forest. Simulated Al leaching from the soil profile is determined mainly by the initial Al content in the soil profile bottom. 
Leaching of $\mathrm{SO}_{4}{ }^{2-}$ is mainly determined by its initial content in the soil and to a lesser extent by redistributed precipitation and $\mathrm{SO}_{4}{ }^{2-}$ deposition.

Focusing on the hypothesis that multivalent cations have an impact on soil organic matter (SOM) matrix and surface characteristics, Schaumann et al. (2013) treat peat and soil samples by solutions of $\mathrm{NaCl}, \mathrm{CaCl}_{2}, \mathrm{AlCl}_{3}$, or with a cation exchange resin. From analysis of the ${ }^{1} \mathrm{H}$ wideline, they distinguish mobile water and water involved in water molecule bridges (WaMB) and find that a large part of cation bridges $(\mathrm{CaB})$ between SOM functional groups are associated with WaMB. The results of this study confirm that water binding in biogeochemical interfaces is controlled by $\mathrm{CaB}-\mathrm{WaMB}$ associations bridging individual SOM segments, and that these bridges lead to changes in water binding, in the degree of confinement of mobile water and in wettability of the sample.

$\mathrm{Xu}$ et al. (2013) estimate the canopy rainfall interception in actual and potential distribution of Qinghai spruce (Picea crassifolia) forest in the inland Heihe River basin (northwestern China). They find that a total of $147 \mathrm{Mt}$ of rainfall is intercepted by the canopy of the actual (disturbed) Qinghai spruce forest. Using Maximum Entropy Species Distribution Modeling, they estimate that after restoration practices a total of $407 \mathrm{Mt}$ of rainfall will be intercepted in the projected potential distribution of the forest.

Yanagawa and Fujimaki (2013) estimate parameter values for drought and salinity stress function of Canola with a widely used macroscopic root water uptake algorithm. They find that Canola is as tolerant as Jatropha to salinity stress. Canola is also found to be less tolerant to drought stress than Jatropha. At the same value, matric potential is more critical than osmotic potential to root water uptake. As a result, Canola may be cultivated as a biofuel crop in arid and semi-arid regions using moderately saline irrigation water.

Dissolved organic carbon (DOC) transported by rivers represents an important link between carbon pools of terrestrial and oceanic ecosystems. Büttner and Tittel (2013) investigate how frequent DOC must be sampled to obtain reasonable load estimates. They find that the amount of DOC in the discharge from a headwater stream at the Ore Mountains (Germany) is underestimated by $13-19 \%$ with monthly, 10-13\% with bi-weekly and $7-9 \%$ with weekly DOC samplings, respectively.

Czachor and Lichner (2013) investigate the potential development of water sorptivity of soil aggregates by heating. They found that the exposure to temperatures between 100 and $200^{\circ} \mathrm{C}$ tends to decrease water sorptivity of aggregates, followed by about two- to four-fold increase in water sorptivity for exposure to temperatures of $250^{\circ} \mathrm{C}$ (in Haplic Luvisol and
Haplic Phaeozem) or $360^{\circ} \mathrm{C}$ (in Haplic Cambisol and Gleyic Mollic Cambisol).

We hope that the present thematic issue and the $3^{\text {rd }}$ Biohydrology conference in Landau will act as a stimulus for initiating new research projects and contribute to finding solutions to the global threats of water scarcity and soil degradation.

\section{REFERENCES}

Bachmann, J., Goebel, M.-O., Woche, S.K., 2013. Small-scale contact angle mapping on undisturbed soil surfaces. J. Hydrol. Hydromech., 61, 3-8.

Büttner, O., Tittel, J., 2013. Uncertainties in dissolved organic carbon load estimation in a small stream. J. Hydrol. Hydromech., 61, 81-83.

Caballero, L.A., Easton, Z.M., Richards, B.K., Steenhuis, T.S., 2013. Evaluating the bio-hydrological impact of a cloud forest in Central America using a semi-distributed water balance model. J. Hydrol. Hydromech., 61, 9-20.

Chanie, T., Collick, A.S., Adgo, E., Lehmann, C.J., Steenhuis, T.S., 2013. Eco-hydrological impacts of Eucalyptus in the semi humid Ethiopian Highlands: the Lake Tana Plain. J. Hydrol. Hydromech., 61, 21-29.

Czachor, H., Lichner, L., 2013. Temperature influences water sorptivity of soil aggregates. J. Hydrol. Hydromech., 61, 84$-87$.

Himmelbauer, M.L., Vateva, V., Lozanova, L., Loiskandl, W., Rousseva, S., 2013. Site effects on root characteristics and soil protection capability of two cover crops grown in South Bulgaria. J. Hydrol. Hydromech., 61, 30-38.

Nikodem, A., Kodešová, R., Bubeníčková, L., 2013. Simulation of the influence of rainfall redistribution in spruce and beech forest on the leaching of $\mathrm{Al}$ and $\mathrm{SO}_{4}{ }^{2-}$ from forest soils. J. Hydrol. Hydromech., 61, 39-49.

Novák, V., 2012. Evapotranspiration in the Soil-PlantAtmosphere System. Springer, Dordrecht.

Schaumann, G.E., Diehl, D., Bertmer, M., Jaeger, A., Conte, P., Alonzo, G., Bachmann, J., 2013. Combined proton NMR wideline and NMR relaxometry to study SOM-water interactions of cation-treated soils. J. Hydrol. Hydromech., 61, 50$-63$.

Xu, Z., Feng, Z., Zhao, C., Zheng, J., Yang, J., Tian, F., Peng, H., Wang, C., Peng, S., Sher, H., 2013. The canopy rainfall interception in actual and potential distribution of Qinghai spruce (Picea crassifolia) forest. J. Hydrol. Hydromech., 61, 64-72.

Yanagawa, A., Fujimaki, H., 2013. Tolerance of canola to drought and salinity stresses in terms of root water uptake model parameters. J. Hydrol. Hydromech., 61, 73-80. 